\title{
An Evaluation of Air-Sea Flux Products for ENSO Simulation and Prediction
}

\author{
M. J. Harrison, A. Rosati, And B. J. Soden \\ National Oceanographic and Atmospheric Administration/Geophysical Fluid Dynamics Laboratory, Princeton, New Jersey \\ E. Galanti AND E. TZIPERMAN \\ Department of Environmental Sciences, The Weizmann Institute of Science, Rehovot, Israel
}

(Manuscript received 5 December 2000, in final form 27 July 2001)

\begin{abstract}
This paper presents a quantitative methodology for evaluating air-sea fluxes related to ENSO from different atmospheric products. A statistical model of the fluxes from each atmospheric product is coupled to an ocean general circulation model (GCM). Four different products are evaluated: reanalyses from the National Centers for Environmental Prediction (NCEP) and the European Centre for Medium-Range Weather Forecasts (ECMWF), satellite-derived data from the Special Sensor Microwave/Imaging (SSM/I) platform and the International Satellite Cloud Climatology Project (ISCCP), and an atmospheric GCM developed at the Geophysical Fluid Dynamics Laboratory (GFDL) as part of the Atmospheric Model Intercomparison Project (AMIP) II. For this study, comparisons between the datasets are restricted to the dominant air-sea mode.

The stability of a coupled model using only the dominant mode and the associated predictive skill of the model are strongly dependent on which atmospheric product is used. The model is unstable and oscillatory for the ECMWF product, damped and oscillatory for the NCEP and GFDL products, and unstable (nonoscillatory) for the satellite product. The ocean model is coupled with patterns of wind stress as well as heat fluxes. This distinguishes the present approach from the existing paradigm for ENSO models where surface heat fluxes are parameterized as a local damping term in the sea surface temperature (SST) equation.
\end{abstract}

\section{Introduction}

ENSO events in the equatorial Pacific occur due to the combined effect of upper ocean dynamics and ocean-atmosphere interaction. A hierarchy of models exists to examine ENSO (Neelin et al. 1998): simple models, containing highly parameterized ocean and atmospheric components; intermediate models, characterized by more complex ocean models; hybrid models, consisting of an ocean GCM coupled to a simpler atmospheric model; and coupled GCMs. Simple, intermediate, and hybrid ENSO models contain air-sea flux components of the general form

$$
\begin{aligned}
\tau^{\prime} & =\mu \mathcal{L}\left(T^{\prime}\right) \\
Q^{\prime} & =\gamma T^{\prime} .
\end{aligned}
$$

Anomalous air-sea momentum exchange, $\tau^{\prime}$, is represented to zeroth order as a nonlocal linear functional, $\mathcal{L}$, of SST anomalies, $T^{\prime}$. Primed quantities are defined with respect to a seasonal climatology. An additional parameter, $\mu$, modulates the level of air-sea wind coupling. The ocean heat flux, $Q^{\prime}$, represents those atmo-

Corresponding author address: M.J. Harrison, NOAA/GFDL, P.O. Box 308, Princeton, NJ 08542.

E-mail: mjh@gfdl.noaa.gov spheric processes which bring SSTs toward equilibrium values. Here, $\gamma$ is a local Newtonian damping coefficient which can, more generally, be a function of location in order to reflect prevailing atmospheric conditions (Syu and Neelin 1995). Over a wide range of the parameter space of such models, instabilities tend to increase with increased wind coupling strength. Chaotic oscillations typically occur in regions of overlap between frequencylocked regimes (Tziperman et al. 1994; Jin et al. 1994; Chang et al. 1994; Tziperman et al. 1995). Thermal coupling, $Q^{\prime}$, regulates instability as well, but this aspect of the air-sea coupling has not been afforded much attention in the literature. Given the importance of airsea coupling for ENSO, a more physically based measure of this quantity seems appropriate. Specifically, the role of radiative and turbulent heat flux anomalies in addition to momentum fluxes can be examined in the context of available data from satellite measurements and atmospheric GCMs.

In this study, we will define an ENSO coupling scheme using a regression based on singular vector decomposition (SVD). The regression will apply to wind stress and heat fluxes. The surface fluxes, as a function of SST, take the resulting form:

$$
\begin{aligned}
\tau^{\prime} & =\mathcal{L}_{\tau}\left(T^{\prime}\right) \\
Q^{\prime} & =\mathcal{L}_{Q}\left(T^{\prime}\right),
\end{aligned}
$$


where $\mathcal{L}_{\tau}$ and $\mathcal{L}_{Q}$ are nonlocal functionals defined by the leading directions of simultaneous covariance in fluxes and SST. We will demonstrate that the consistent treatment of heat and momentum fluxes provides a more direct insight into the nature of anomalous air-sea exchange during ENSO events. Furthermore, the omission of tunable heat flux and wind stress coupling parameters allows us to make quantitative assessments of different atmospheric products.

Atmospheric reanalyses from the European Centre for Medium-Range Weather Forecasts (ECMWF) and the National Centers for Environmental Prediction (NCEP) are included in our analysis. These products represent the merging of atmospheric observational networks with GCMs over an extended retrospective period using a consistent data assimilation and model framework [Gibson et al. (1997) and Kalney et al. (1996)]. Surface fluxes derived from satellite measurements are also included in this study. Latent heat and momentum fluxes are retrieved from the Special Sensor Microwave/Imager platform (SSM/I; Jost et al. 1999) and radiative fluxes are derived from the International Satellite Cloud Climatology Project (ISCCP) D3 dataset (Darnell et al. 1996). Directional information for the SSM/I winds are provided by the ECMWF analysis. Lastly, surface fluxes provided by the Geophysical Fluid Dynamics Laboratory (GFDI) Atmospheric Model Intercomparison Project (AMIP) II run are analyzed (Gordon and Stern 1982).

Section 2 describes how the coupled model is constructed. Section 3 provides a general description of airsea regressions derived from the various atmospheric products. Results from long integrations and retrospective forecasts using the linear atmospheric models based on the various atmospheric products are presented in section 4 . This section also contains a discussion of the sensitivity of the coupled model results to the regression method and to the training period for the statistical models. Section 5 is a summary discussion with some conclusions and proposals for future work.

\section{Model design}

\section{a. Ocean model}

The ocean model is the GFDL Modular Ocean Model, version 3 . The domain extends from roughly $40^{\circ} \mathrm{N}$ to $40^{\circ} \mathrm{S}$ and from $120^{\circ} \mathrm{E}$ to $70^{\circ} \mathrm{W}$. It consists of 16 fixed vertical levels with 10 levels within $250 \mathrm{~m}$ of the surface. The vertical mixing parameterization of Philander and Pacanowski (1981) and the horizontal mixing based on the work of Smagorinsky (1963) are used.

The ocean model is spun up from a rest state with observed temperature and salinity (Levitus and Boyer 1994; Levitus et al. 1994) using climatological surface fluxes. The monthly wind stress is from the Florida State University (FSU) pseudostress analysis (Stricherz et al. 1997). A constant air density of $1.2 \mathrm{~kg} \mathrm{~m}^{-3}$ and a non- dimensional drag coefficient of 0.0012 were chosen. Outside the FSU domain $\left(30^{\circ} \mathrm{N}\right.$ to $\left.30^{\circ} \mathrm{S}\right)$, the FSU winds are merged with climatological winds from Hellerman and Rosenstein (1983). Monthly heat fluxes are from Esbensen and Kushnir (1981), plus a restoring term to observed SST. Surface salinities are restored towards climatological values in lieu of freshwater fluxes. Surface fluxes for the spin up run are summarized as follows:

$$
\begin{aligned}
\boldsymbol{\tau} & =\overline{\boldsymbol{\tau}}^{\mathrm{obs}}(t) \\
Q & =\bar{Q}^{\mathrm{obs}}(t)+\gamma_{1}\left[T-\bar{T}^{\mathrm{obs}}(t)\right] \\
F_{s} & =\beta\left[S-\bar{S}^{\mathrm{obs}}(t)\right] .
\end{aligned}
$$

Here, $\boldsymbol{\tau}, Q$, and $F_{s}$ are vector momentum, surface heat, and salinity flux, respectively; $\gamma_{1}=-50 \mathrm{~W} \mathrm{~m}^{-2}{ }^{\circ} \mathrm{C}^{-1}$, $\beta=-0.01 \mathrm{~kg} \mathrm{~m}^{-2} \mathrm{~s}^{-1}$ (PSU) $^{-1}$, and $\bar{T}^{\text {obs }}$ and $\bar{S}^{\text {obs }}$ are observed monthly varying climatological SST and sea surface salinity, respectively (Levitus and Boyer 1994; Levitus et al. 1994). The temperature and salinity restoring correspond roughly to a 5-day damping timescale for the top model level thickness. Overbar denotes monthly climatological values.

Figure 1 is a comparison with observational estimates (Levitus and Boyer 1994; Levitus et al. 1994) after integrating the ocean model for $25 \mathrm{yr}$ using the surface forcing from [(2.3a)-(2.3c)]. The top panel of the figure shows a section along the equator and demonstrates that the ocean model has a $1-2^{\circ} \mathrm{C}$ cold bias throughout much of the upper $300 \mathrm{~m}$. A slight warm bias exists in the warm pool region along the equator and in the eastern equatorial Pacific near $100 \mathrm{~m}$. The bottom panel is a zonal average across the Pacific basin. A $1-2^{\circ} \mathrm{C}$ cold bias is observed through most of the subsurface on either side of the equator. The SST seasonal cycle along the eastern equatorial Pacific is shown in Fig. 2. The amplitude, phase, and westward propagation of the seasonal cycle are in good agreement with observations. The model has a SST cold bias of approximately $1^{\circ} \mathrm{C}$ in the eastern Pacific. The model cold bias is most likely attributable to deficiencies in the wind forcing and the vertical mixing. Stockdale et al. (1998) provide an account of this familiar cold tongue bias which has been documented in similarly configured ocean GCMs.

Although biases exist in the ocean model climatology, it is a reasonable representation of the ocean consistent with similarly configured ocean models at this resolution. Results using the statistical atmosphere, which will be presented in the following sections, are sensitive to the ocean background state. In particular, the position of the thermocline in the upwelling region in the eastern Pacific controls the level of SST sensitivity to changes in atmospheric winds.

The restoring heat flux term [second term in (2.3b)] and the model SSTs are averaged over the final $10 \mathrm{yr}$ of the 25-yr spin up run. The heat flux equation is subsequently modified as follows: 

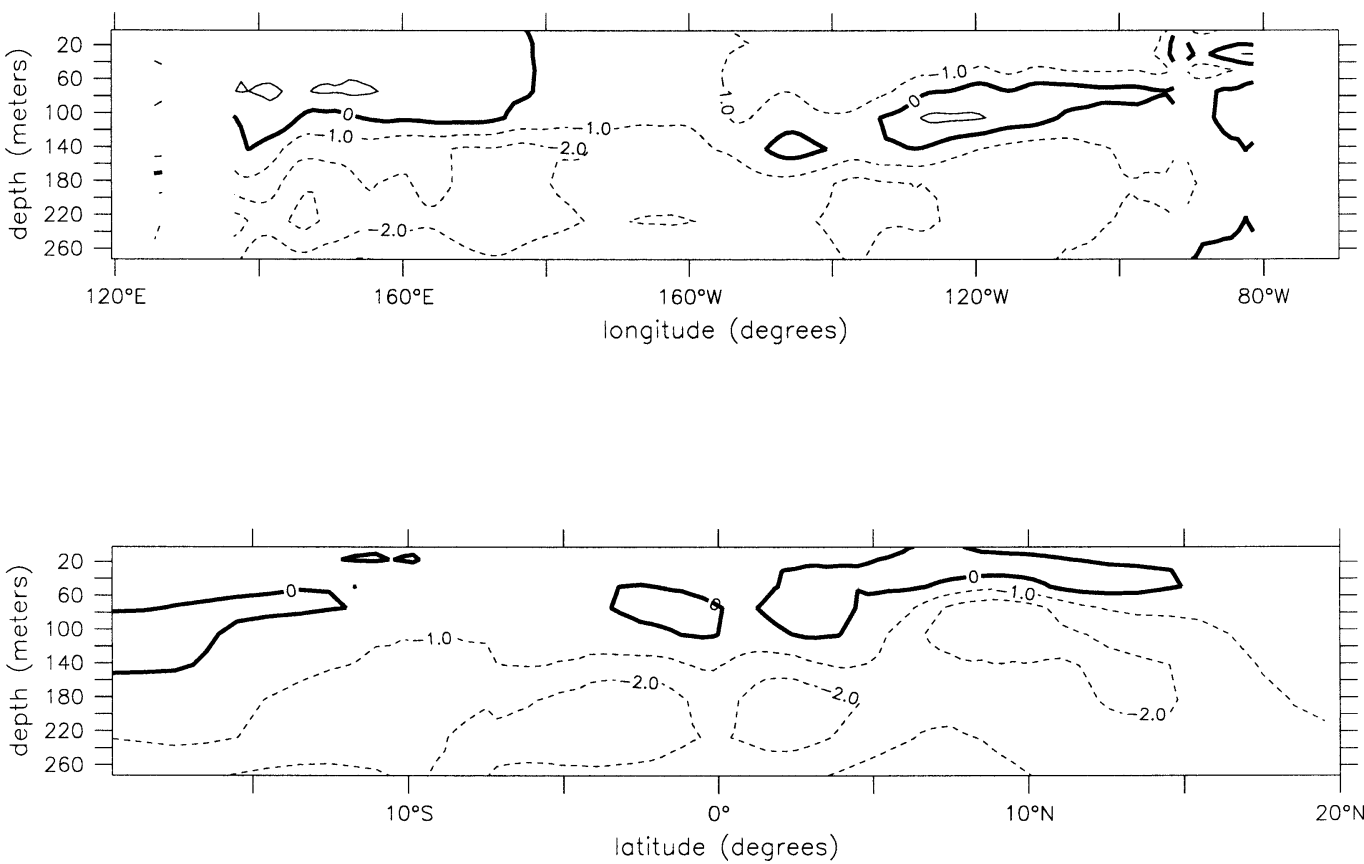

FIG. 1. Ocean model annual mean climatology minus observational estimates from Levitus and Boyer (1994) for the upper $300 \mathrm{~m}\left({ }^{\circ} \mathrm{C}\right)$. (top) A section along the equator, and (bottom) the zonal average from $120^{\circ} \mathrm{E}$ to $80^{\circ} \mathrm{W}$.

$$
Q=\bar{Q}^{\mathrm{obs}}(t)+\bar{Q}^{\mathrm{adj}}(t)+\gamma_{2} T^{\prime},
$$

where $\bar{Q}^{\text {adj }}(t)$ is the monthly climatology of the restoring term (2.3b), $T^{\prime}$ is the SST anomaly defined with respect to the model monthly climatology and $\gamma_{2}=-1 \mathrm{~W} \mathrm{~m}^{-2}$ ${ }^{\circ} \mathrm{C}^{-1}$ or a 100-day restoring timescale. The heat flux forcing in (2.4) results in a stable ocean background state, with a very modest local damping factor that prevents long-term drift. Atmospheric flux anomalies are added to the climatological heat fluxes (2.4) and the wind stress (2.3a) for the coupled runs. Results that will be presented are not very sensitive to changes to $\gamma_{2}$, although it is important that this term is small in comparison to the statistically based heat flux feedbacks, which will be discussed in the following section.

\section{b. Statistical atmospheric model}

The atmospheric flux anomalies, $\tau^{\prime}$ and $Q^{\prime}$, are based on least squares linear regression of momentum and heat fluxes to SST. The heat flux is separated into latent and radiative components. Sensible and freshwater flux anomalies are not incorporated in the model at this time,
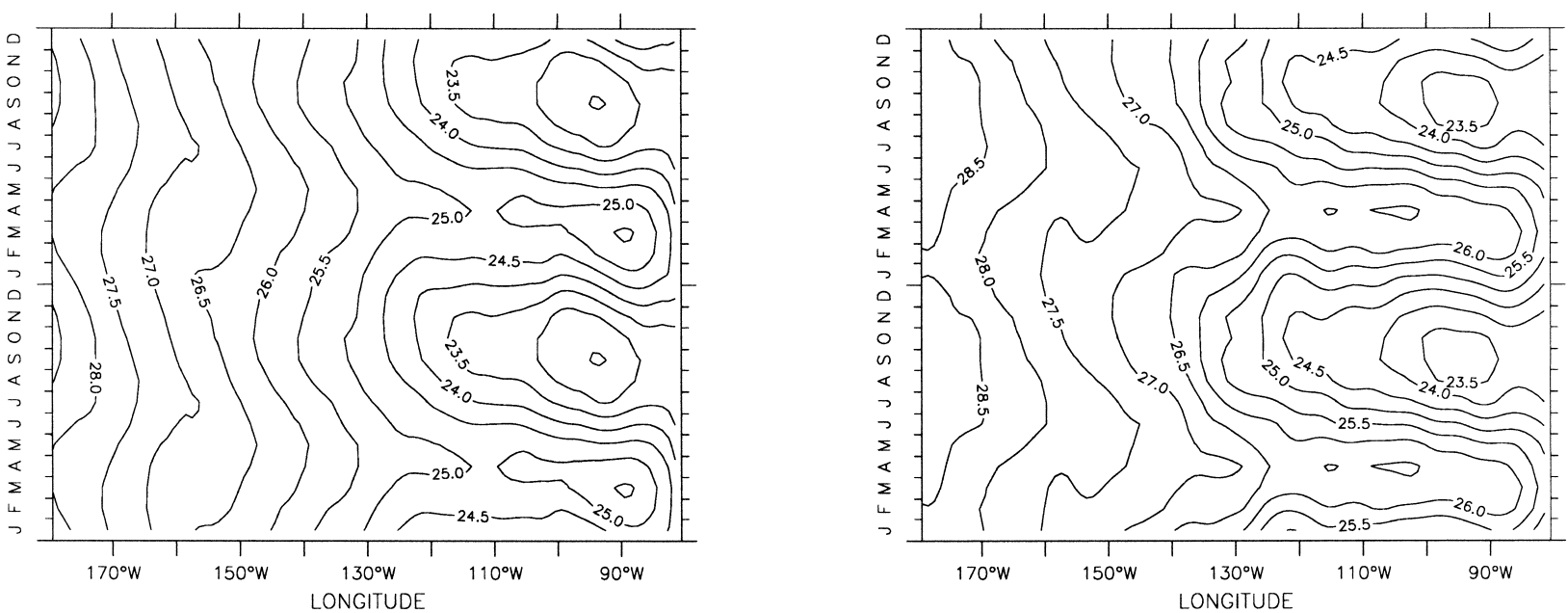

FIG. 2. Seasonal cycle of SST $\left(5^{\circ} \mathrm{S}-5^{\circ} \mathrm{N}, 5\right.$-month running mean) from the (left) spinup run and (right) Levitus and Boyer (1994). Contour interval is $0.5^{\circ} \mathrm{C}$. 
since their impact on SST in the Tropics is typically much smaller [the local damping term in Eq. (2.4) can be considered a proxy for sensible feedbacks].

$$
\begin{aligned}
\tau^{\prime} & =\mathcal{L}_{\tau}\left(T^{\prime}\right) \text { and } \\
Q^{\prime} & =\mathcal{L}_{\text {evap }}\left(T^{\prime}\right)+\mathcal{L}_{\text {rad }}\left(T^{\prime}\right) .
\end{aligned}
$$

The above terms are based on a SVD of the vector wind stress, latent heat, and net radiation covariance with SST. Each set of patterns is calculated separately. Data are interpolated onto a $3^{\circ}$ grid over the Pacific domain from $20^{\circ} \mathrm{S}$ to $20^{\circ} \mathrm{N}$. Monthly means over the length of the dataset are extracted to produce interannual anomalies, which are detrended prior to forming the covariance matrix. Detrending is based on a least squares linear fit to the component flux and SST time series. The SST anomalies are from the Reynolds analysis (Reynolds and Smith 1994). The Numerical Algorithms Group routine F02WEF is used to calculate the singular vectors. The elements of the covariance matrix, $\mathbf{C}$, are calculated

$$
C_{i, j}=\frac{\sum_{n=1}^{N}\left(t_{i}^{n} f_{j}^{n}\right)}{N-1},
$$

where $t_{i}^{n}$ are observed SST anomalies and $f_{j}^{n}$ are surface flux anomalies at locations $i$ and $j$ occurring at time $n$. This $N_{i} \times N_{j}$ matrix can be decomposed into two orthonormal sets of vectors such that

$$
\mathbf{C f}_{k}^{*}=\lambda_{k} \mathbf{t}_{k}^{*}, \quad \mathbf{C}^{\mathrm{T}} \mathbf{t}_{k}^{*}=\lambda_{k} \mathbf{f}_{k}^{*} .
$$

There are $R$ nonzero eigenvalues, $\lambda_{k}^{2}$, where $R \leq$ $\min \left(N_{i}, N_{j}, N-1\right)$. Here, $\mathbf{f}_{k}^{*}$ and $\mathbf{t}_{k}^{*}$ are the unit length eigenvectors of $\mathbf{C C}^{\mathrm{T}}$ and $\mathbf{C}^{\mathrm{T}} \mathbf{C}$, respectively (see Bretherton et al. 1992 for a more complete review). The unit normalized inner product between the SST anomalies and the SST singular vector,

$$
\alpha_{k}^{n}=\hat{\sigma}_{k}^{t-1} \mathbf{t}^{n^{\mathrm{T}}} \mathbf{t}_{k}^{*},
$$

where $\hat{\sigma}_{k}^{t}$ is the estimated standard deviation of the time series coefficient for SST, is used as a predictor for flux estimates, $\hat{\mathbf{f}}_{k}^{n}$, corresponding to mode $k$

$$
\hat{\mathbf{f}}_{k}^{n}=\alpha_{k}^{n} \hat{\mathbf{b}}_{k}, \quad \hat{b}_{j, k}=\frac{\sum_{n=1}^{N}\left(\alpha_{k}^{n} f_{j}^{n}\right)}{N-1} .
$$

Here, $\hat{\mathbf{b}}_{k}$ is a regression vector of length $N_{j}$ defined by the covariance between the flux anomalies, $f_{j}$, and the normalized predictor variable, $\alpha_{k}$. The regressed fluxes are a least squares estimate of the surface fluxes based on predictor patterns of SST anomalies. The regression vectors are equivalent to the heterogeneous correlation maps (Bretherton et al. 1992) multiplied by the standard deviation of the fluxes at each point. Syu and Neelin (1995) used the flux singular vectors, $\mathbf{f}^{*}$, in place of the regression vectors, $\hat{\mathbf{b}}$. Newman and Sardeshmukh (1995) discuss the deficiencies in this approach. However, for the leading mode analyses presented in sections 3 and
4 , the results are similar if the flux singular vectors are used in place of the regression vector.

The coupled model is composed of the ocean GCM subject to climatological fluxes (2.3a), (2.3c) and (2.4) plus wind stress, and evaporative and radiative anomalies (2.9). The coupled model is initialized from a given state (some deviation from the model climatology) and the flux anomalies are calculated once per day. An important aspect of the coupled model is that the local temperature-restoring forces in the model are negligible. The present statistical atmospheric model, it is argued, provides a more physically consistent framework for evaluating air-sea coupling than the type described in Eq. (1.1a).

For this work, the comparison between atmospheric products is limited to single predictor models based on the leading mode $(k=1)$. Section 3 provides a detailed physical interpretation of the leading coupled modes. This is an important component to this study since it is argued that additional coupled modes should be subject to similar physically based descriptions. Sensitivity of the results to inclusion of additional modes will be discussed in section $4 \mathrm{c}$ along with an examination of the impact of using a different SST predictor.

\section{Regression patterns}

Four atmospheric products are considered in this study: two atmospheric reanalyses from ECMWF and NCEP, the GFDL AMIP II model, and a satellite product combining SSM/I and ISCCP measurements (SAT). The NCEP and ECMWF reanalyses and the GFDL datasets are analyzed for the period beginning in 1979 and ending in 1993. The SSM/I wind and evaporative fluxes were available from 1988 to 1996 and the cloud forcing was available from 1983 to 1991. All of the analysis periods coincide, with the exception of the SAT datasets. Differences in the analyses for the other products based on the SAT time periods compared with the 1979-93 period were small in comparison to the differences between products. The discrepancies outlined below are therefore, in large part, attributable to inherent characteristics of the atmospheric datasets.

The leading regression patterns indicate equatorward (poleward) and eastward (westward) shifts in the tropical convective zones associated with warming (cooling) in the cold tongue region. For example, the leading mode from the ECMWF reanalysis is shown in Fig. 3. $\mathrm{A}+1^{\circ}$ eastern-central equatorial Pacific SST anomaly corresponds roughly to a 0.2 dyn $\mathrm{cm}^{-2}\left(0.02 \mathrm{~N} \mathrm{~m}^{-2}\right)$ westerly wind stress anomaly near the date line. Latent cooling over the cold tongue increases by roughly 20 $\mathrm{W} \mathrm{m}{ }^{-2}$. Near the date line, the latent cooling is reduced (ocean warming tendency) by approximately $8 \mathrm{~W} \mathrm{~m}^{-2}$. Net surface radiation near the date line reduces (ocean cooling tendency) by approximately $20 \mathrm{~W} \mathrm{~m}^{-2}$ and this extends well to the east. Each flux component is associated with a separate SST predictor pattern. Only the 
ECMWF WINDS MODE 1 (a)
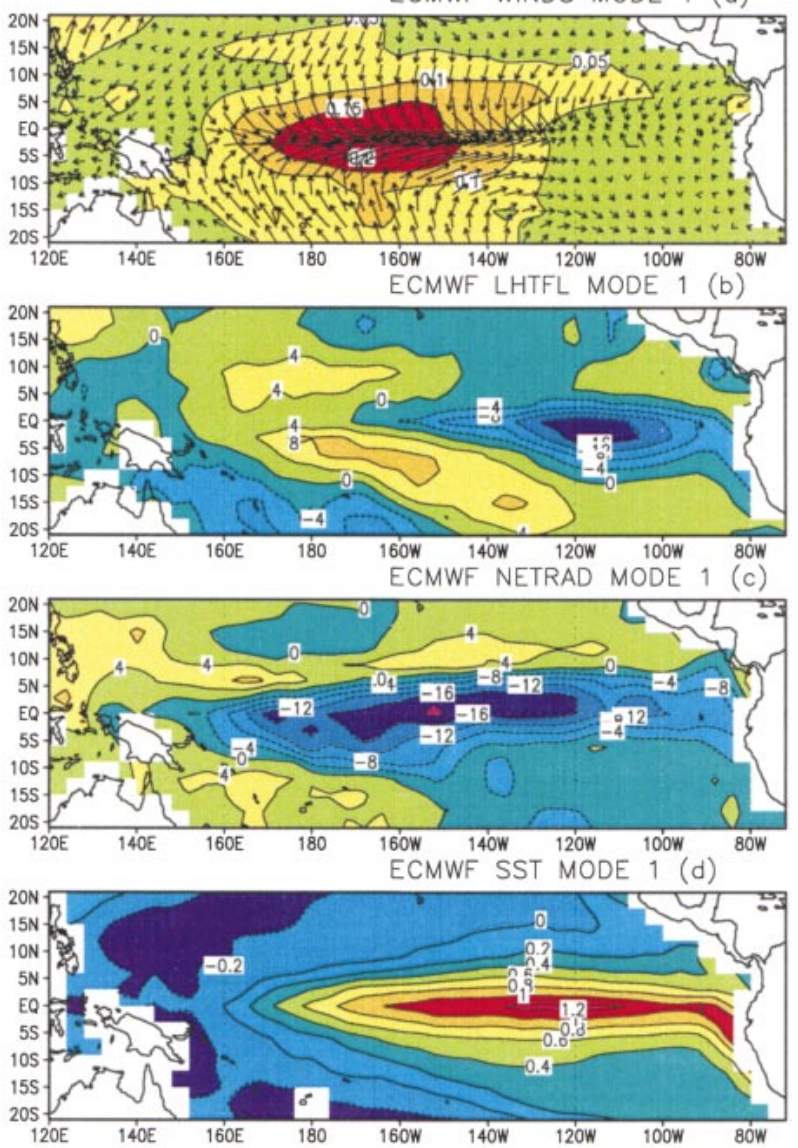

FIG. 3. Mode 1 regression patterns from the ECMWF reanalysis. Top to bottom: wind stress anomalies $\left(\mathrm{dyn} \mathrm{cm}^{-2}\right)$; downward latent flux anomalies $\left(\mathrm{W} \mathrm{m}^{-2}\right)$; net downward surface radiation $\left(\mathrm{W} \mathrm{m}^{-2}\right)$; and SST anomalies $\left({ }^{\circ} \mathrm{C}\right)$. The regressions account for $9 \%$ and $14 \%$ of the zonal and meridional wind stress, respectively, and $4 \%$ and $6 \%$ of the latent and radiative fluxes.

wind stress predictor pattern is shown in the figures since the component patterns are nearly identical.

Changes over the cold tongue are due to destabilization of the boundary layer (Deser and Wallace 1990). As SSTs in this region warm, the overlying atmosphere becomes more unstable and evaporation increases as a result. Near the date line, enhanced cloudiness and westerly winds are associated with the eastward movement of the South Pacific convergence zone (SPCZ). Lowerlevel winds converge to the west of the maximum SST anomalies to supply the mass and energy to balance the more frequent occurrence of penetrative convection in this region. Surface evaporation in these regions weakens in association with a reduction in surface wind speed. Net surface radiation tends to decrease over the warmer waters as cloudiness increases, while regions that are normally cloudy, the climatological locations of the intertropical convergence zone (ITCZ) and SPCZ, show an increase in surface radiation.

These features of the atmospheric response are qual-
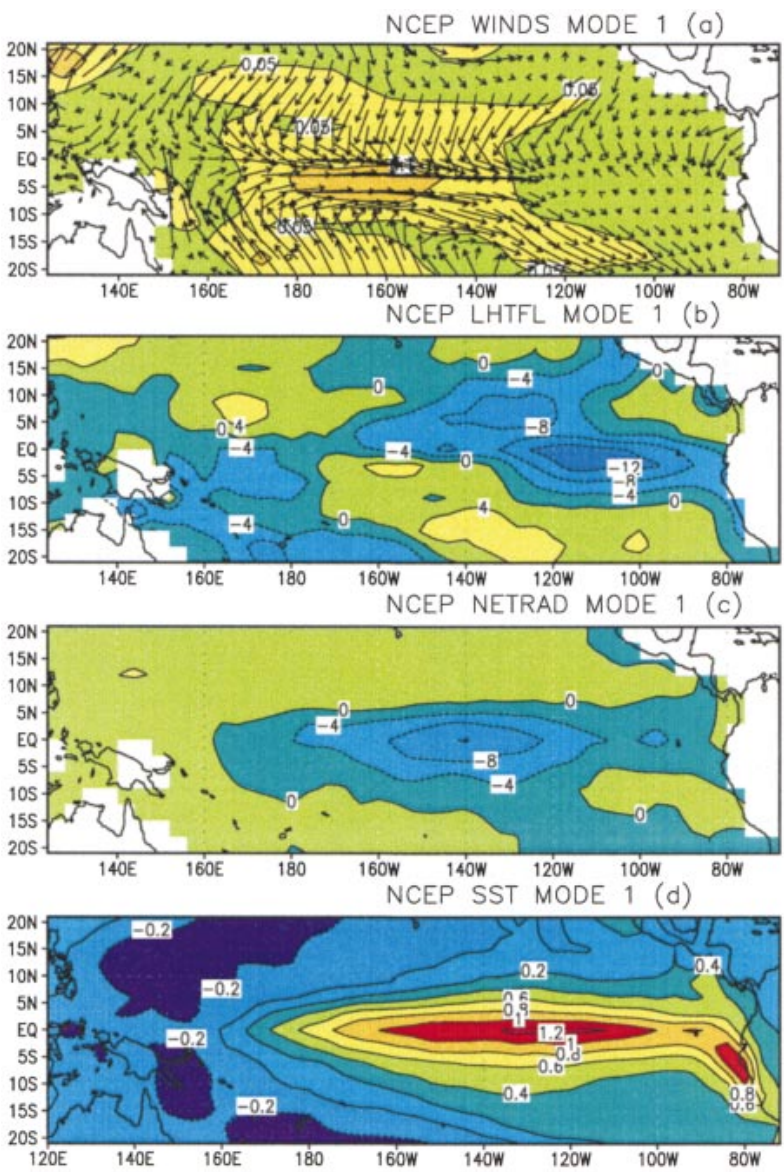

FIG. 4. As in Fig. 3 except for NCEP reanalysis. The regressions account for $6 \%$ and $9 \%$ of the zonal and meridional wind stress, respectively, and $5 \%$ and $10 \%$ of the latent and radiative fluxes.

itatively reproducible between the various atmospheric products considered in this study. This points to the rather straightforward nature of ENSO air-sea interaction, which mostly involves the modulation of organized regions of convection, that is, during warm events, convection shifts eastward and during cold events it retreats westward. As such, differences in the ENSO patterns of various atmospheric products are largely associated with differences in the climatological structure and location of their respective convergence zones.

The NCEP reanalysis, GFDL, and SAT leading regression patterns are shown in Figs. 4, 5, and 6, respectively. The SST predictor patterns are similar in all cases. Qualitatively, the atmospheric response patterns match between the products, that is, westerly winds in the central Pacific, increased evaporation over the cold tongue, and enhanced cloudiness in the central Pacific. There are, however, notable differences: the NCEP fluxes are as much as 50\% less than ECMWF's, the GFDL fluxes are located approximately $20^{\circ}$ further west than the other products, and the SAT product shows a relatively large, $20 \mathrm{~W} \mathrm{~m}^{-2}$, reduction in evaporative cooling in the central Pacific. 
AMIP2 WINDS MODE 1 (a)
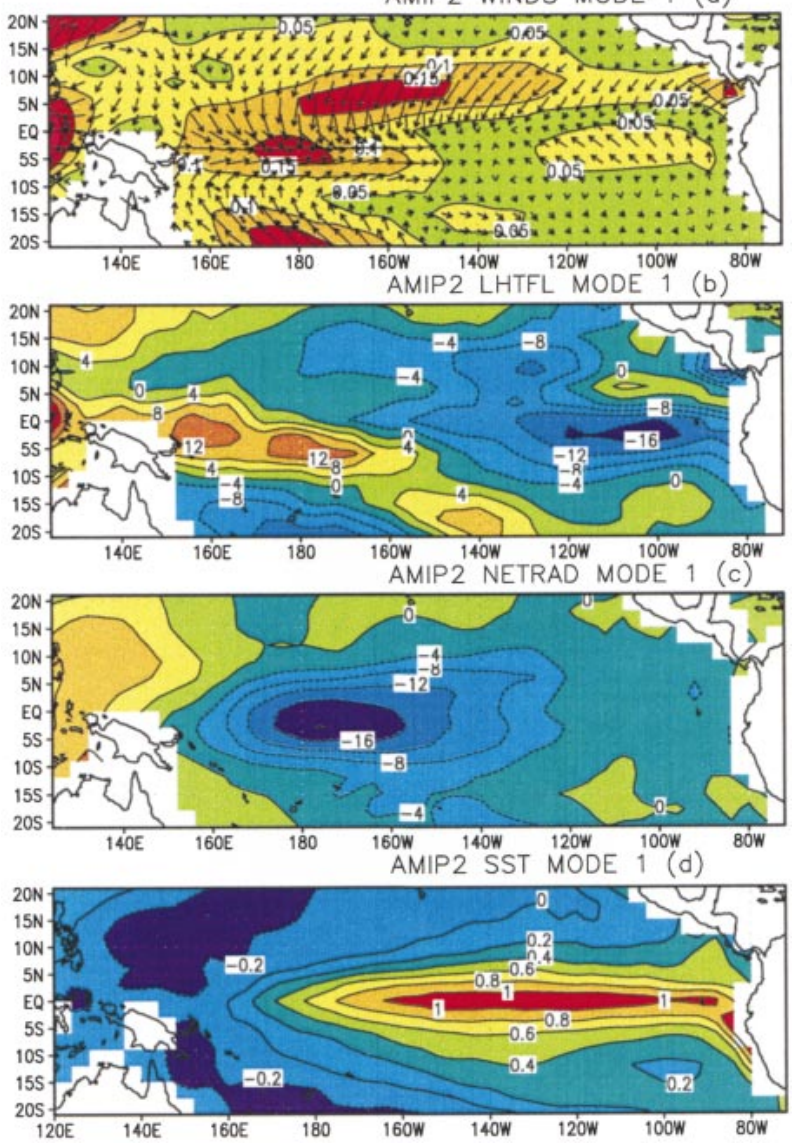

FIG. 5. As in Fig. 3 except for GFDL AMIP II model. The regressions account for $10 \%$ and $13 \%$ of the zonal and meridional wind stress, respectively, and $8 \%$ and $16 \%$ of the latent and radiative fluxes.

It is beyond the scope of this work to analyze in detail the sources of the discrepancies in these atmospheric products. Our present interest is restricted to understanding the implications of these differences for ENSO modeling.

\section{Coupled model results}

This section presents comparisons between different atmospheric models based on the flux products described in section 3 coupled with the ocean GCM described in section 2a. The stability of the coupled model solutions is compared in section $4 \mathrm{a}$. In section $4 \mathrm{~b}$, the atmospheric products are compared based on retrospective forecast skill for Niño-3 region SST. Sensitivity of the results to the training period, an alternate regression model, the inclusion of additional air-sea modes, and seasonally based air-sea coupling is presented in section $4 c$.

\section{a. ENSO as a self-sustained or damped oscillator?}

Hybrid-coupled model averaged SST anomalies for the Niño-3 region $\left(5^{\circ} \mathrm{S}\right.$ to $5^{\circ} \mathrm{N}, 150^{\circ} \mathrm{W}$ to $\left.90^{\circ} \mathrm{W}\right)$ are
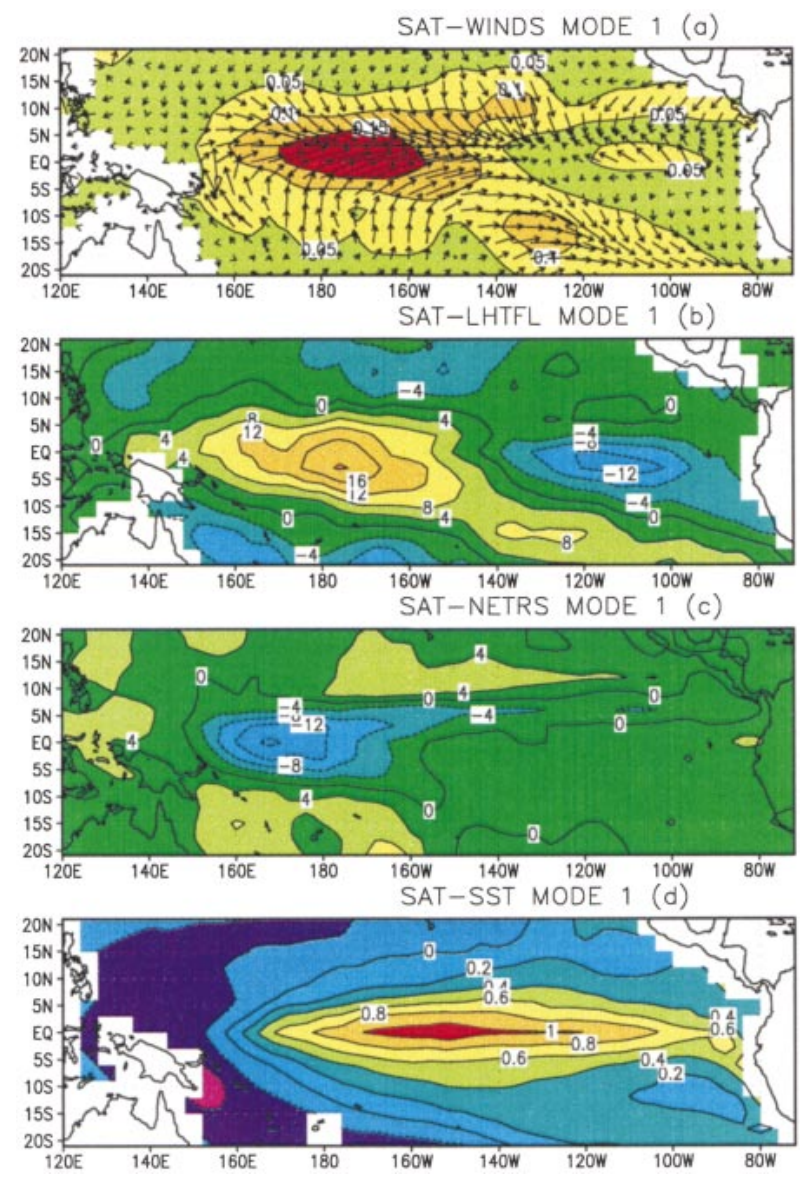

FIG. 6. As in Fig. 3 except for satellite products. The regressions account for $8 \%$ and $10 \%$ of the zonal and meridional windstress, respectively, and $3 \%$ and $8 \%$ of the latent and radiative fluxes.

shown in Fig. 7. The ECMWF model yields sustained regular oscillations when coupled with the ocean model. The oscillation period is approximately three years. The NCEP model results in a damped oscillatory mode with an approximate decay timescale of three to four years. The GFDL model also produces a damped mode with a yet shorter decay timescale of approximately one year. The SAT model is unstable and nonoscillatory. The Niño-3 anomalies are calculated by subtracting the monthly climatology from the spinup run shown in Fig. 2. All of the models are producing oscillations around the background state of the ocean model with the exception of the SAT model, which drifts to a warm climate state. The annual oscillations shown in the SAT model are due to a shift in the seasonal cycle associated with the coupled model drift.

As discussed in section 3, the ECMWF wind stress regression coefficients in the central Pacific exceed 0.2 dyn $\mathrm{cm}^{-2}$ while the NCEP anomalies are approximately $0.1 \mathrm{dyn} \mathrm{cm}^{-2}$, which might account for the differences in stability between these two coupled models. The GFDL wind stress magnitude is, however, comparable to ECMWF's but the GFDL flux anomalies yield the 


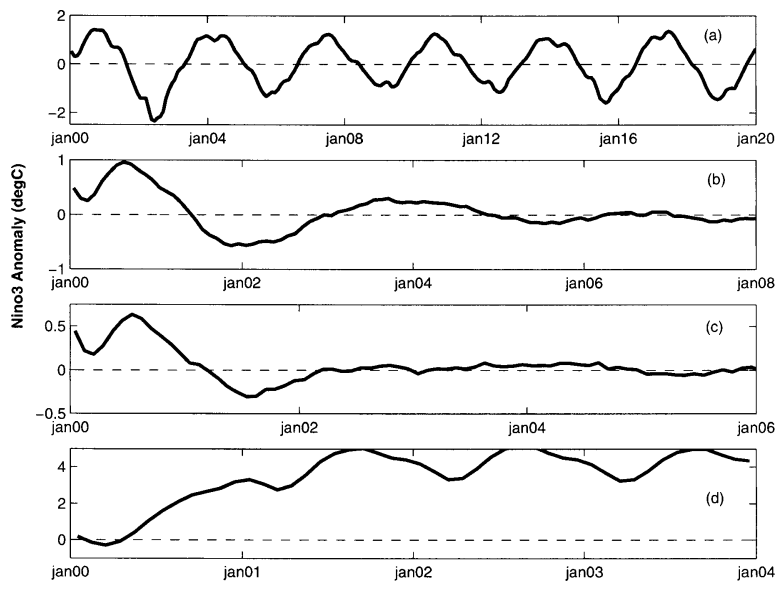

FIG. 7. Niño-3 SST anomalies based on the hybrid coupled model runs using (a) ECMWF, (b) NCEP, (c) GFDL, and (d) SAT fluxes.

most stable oscillations. The magnitude of the wind stress alone, therefore, does not determine coupled model stability. The reasons for this lack of sensitivity to the wind stress magnitude lies in our treatment of the heat flux feedbacks.

In contrast to ENSO models based on atmosphereocean coupling of type (1.1a) and (1.1b), where the SST damping term is considered independently of the wind stress, the present approach combines the two. Indeed, it is physically plausible that the surface heat flux anomalies are strongly tied to wind anomalies. For instance, wind anomalies in the central Pacific are linked to shifts in the Walker circulation which carries with it changes in cloudiness and surface evaporation.

The coupled model stability is more sensitive to the zonal location of the feedbacks in this model framework. Idealized experiments were performed by specifying a Gaussian-shaped zonal wind stress anomaly pattern and spatially constant local heat flux feedbacks. The zonal and meridional scales of the Gaussian anomaly pattern were set to approximately $54^{\circ}$ and $5^{\circ}$, respectively, which are similar to the scales observed in the reanalyses. The SST predictor was identical to the pattern used in the ECMWF coupled model. The local heat flux damping was set to approximately $-10 \mathrm{~W} \mathrm{~m}^{-2}{ }^{\circ} \mathrm{C}^{-1}$. The hybrid model becomes more damped as the winds are moved westward (Fig. 8). This partly explains why the GFDL hybrid model was the most stable since the flux anomaly patterns are shifted westward relative to the other products as discussed in section 3 .

The nonoscillatory instability in the case of the SAT model is the result of the comparatively large evaporative flux anomaly in the central equatorial Pacific. This was verified by replacing the SSM/I evaporation anomalies with the ECMWF anomalies, in which case the model produced stable oscillations.

\section{b. Retrospective Niño-3 hindcasts}

An important measure of the accuracy of the atmospheric flux anomalies is how well the models are able
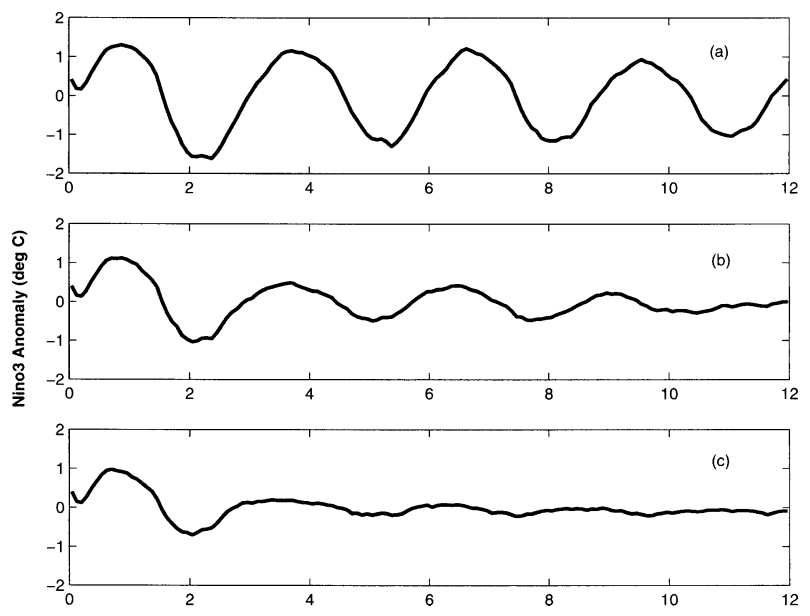

FIG. 8. Coupled model Niño-3 anomalies $\left({ }^{\circ} \mathrm{C}\right)$ based on a Gaussian zonal wind stress anomaly coupling pattern centered at (a) $170^{\circ} \mathrm{W}$, (b) $180^{\circ} \mathrm{W}$, and (c) $170^{\circ} \mathrm{E}$. A spatially uniform heat flux damping was applied.

to predict ENSO events. The coupled models were provided with ocean initial conditions from the GFDL ocean temperature assimilation system (Rosati et al. 1997), which is similar to the ocean initialization system used operationally at NCEP (Behringer et al. 1998) for seasonal forecasting. The ocean initialization run was forced with FSU winds and surface and subsurface in situ temperature data were assimilated into the model using a statistical interpolation scheme. Hindcasts were made from 1981 through 1997 from 1 January initial conditions for lead times up to 24 months. The SAT model was not included in this comparison since the results from the long coupled run were considered unrealistic. Niño-3 correlations for the reanalysis models were greater than 0.6 through 6 months and rms errors dropped below persistence errors after 4 months (Fig. 9). The model correlation skill was much greater during the 1980s and showed a marked drop-off during the 1990s. The El Niño events in 1982, 1987, and 1997 were successfully predicted by the reanalysis hindcast models along with the 1988 La Niña event, although the magnitude of the events was consistently underpredicted. The GFDL hybrid model results in a precipitous drop in skill in the first 4 months of the hindcast. The quality of the hindcasts was assessed based on 1 July hindcast starts and the relative skill of the models was the same (not shown). Comparisons of hindcast SST anomaly correlation with observed values from Reynolds and Smith (1994) are shown in Fig. 10. Shown are maps for 6-month hindcasts from January initial conditions. Correlations greater than 0.5 are shaded. The top two panels are maps for the ECMWF and NCEP hybrid models, respectively. The lower panel is a map for the GFDL hybrid model. Correlation skills exceed 0.5 over most of the eastern equatorial Pacific for the reanalyses and are considerably lower for the GFDL model. Despite having reasonably good ocean initial 

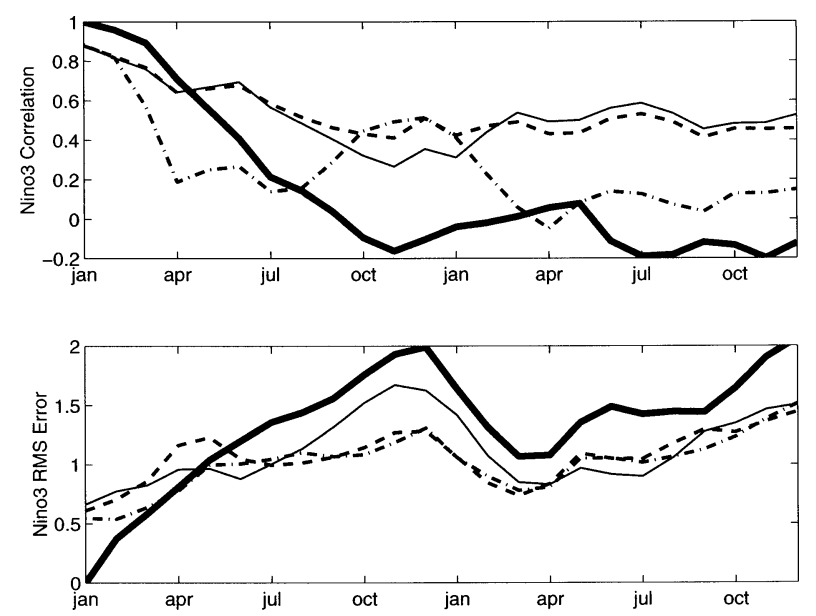

FIG. 9. (top) Niño-3 SST hindcast correlation skill and (bottom) rms error initialized in Jan using FSU winds and subsurface data assimilation. Persistence (thick solid), NCEP (thin solid), ECMWF (dashed), and GFDL (dash-dot). The units for rms error are ${ }^{\circ} \mathrm{C}$.

conditions, evidenced by the success of the reanalysis models in predicting the ENSO events of the 1980s and 1997, the GFDL model performed poorly in these cases since the initial perturbations were not successfully amplified by the air-sea interactions that are subcritical (Fig. 7). Although the NCEP coupled model is damped, it is less strongly damped than the GFDL model. These results highlight the relevance of the air-sea coupling factors for prediction, particularly for anomaly coupled GCM forecast systems (Ji et al. 1998). The GFDL hybrid model should, perhaps, be expected to perform poorly in the hindcast comparison with the reanalysisbased models since the GFDL AMIP II model is not constrained by observations. Furthermore, the training period for the reanalyses coincides with most of the hindcast period.

\section{c. Sensitivity of coupled model results}

The regression values are sensitive to the time period of analysis. This is particularly true in the case of the reanalysis regression models. For instance, the NCEP reanalysis exhibits a marked change in the tropical circulation near 1979. As a result, regressions based on the pre-1979 data produce sustained oscillations in the coupled model compared with the post-1979 data, which produces damped oscillations. Inhomogeneities in the reanalyses are at least partly related to changes in the observational network, for instance the introduction of satellite data. Statements about the implications of the various flux datasets for ENSO stability are therefore limited by uncertainty regarding stationarity of the statistics of the products themselves.

As discussed, this study is focused on comparing the leading air-sea mode between the various hybrid coupled models. However, several coupled model runs were made to examine the sensitivity to additional coupled

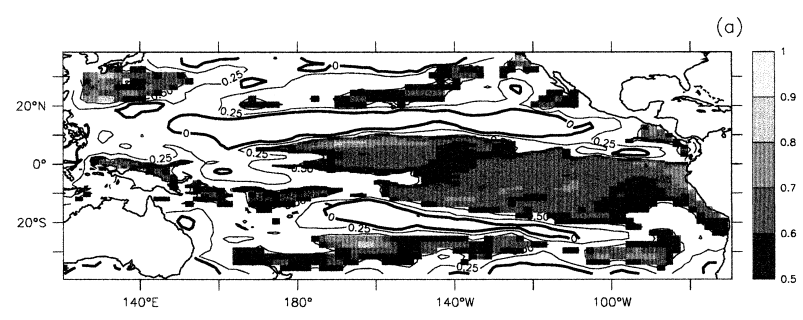

(b)

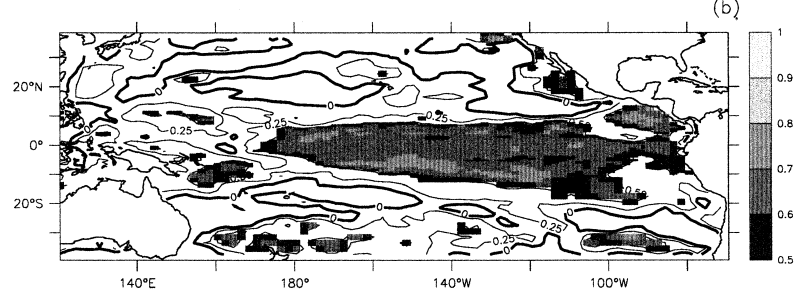

(c)

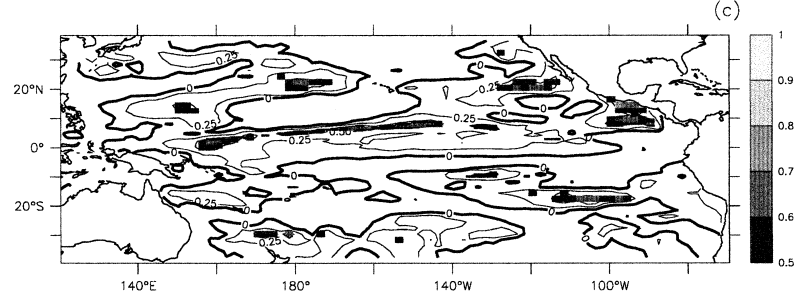

FIG. 10. Jun SST hindcast correlation skill (from 1 Jan initial conditions) for the (a) ECMWF, (b) NCEP, and (c) GFDL coupled models.

modes. The addition of mode 2 to the coupled models did not have a substantial impact on the oscillatory behavior and/or the predictive skill for any of the models examined in this study. The ECMWF model with the leading three air-sea modes did, however, show sensitivity. The amplitude of the oscillations is reduced in this model and the period of oscillation lengthens to approximately 7 years. The spatial distribution of SST anomalies in the model degrades with respect to the mode 1 and 2 models with off-equatorial anomalies near $10^{\circ} \mathrm{S}, 140^{\circ} \mathrm{W}$, which are significantly larger than observed (not shown). This added variability is driven in the model by local radiative feedbacks. A detailed examination of additional coupled modes is a topic for future study. A more careful statistical analysis would need to be performed, for instance, using ensembles of atmospheric datasets in order to assess the statistical significance of additional coupled modes. While such an analysis could be performed for the GFDL dataset since ensemble runs are available, this is not the case for the reanalyses and satellite data.

In order to assess the sensitivity of our results to the choice of the SST predictors, an EOF-based regression is calculated by computing the EOFs of the SST covariance matrix and regressing the fluxes against the time series of projection coefficients for SST. The SVD 
TABLE 1. Residual sum of squares (RSS) from regression model for NCEP fluxes based on 1, 2, and 3 leading predictor patterns. The RSS values are based on SVD and EOF-based predictors, respectively. Here, RSS is expressed as a percentage of original variance.

\begin{tabular}{lccc}
\hline \multicolumn{1}{c}{ Flux } & 1 & 2 & 3 \\
\hline Zonal wind stress & $94.3,94.4$ & $91.1,91.6$ & $89.4,90.5$ \\
Meridional wind stress & $91.2,91.2$ & $88.0,88.0$ & $84.7,87.1$ \\
Latent heat flux & $95.5,95.5$ & $92.9,93.0$ & $91.3,91.4$ \\
Radiative heat flux & $89.6,89.6$ & $86.5,86.4$ & $85.1,84.9$ \\
\hline
\end{tabular}

regression values were compared with regressions based on the EOFs. Table 1 shows the residual sum of squares (RSS) as a percentage of the original flux variance for the NCEP reanalysis. The basin-average RSS values are statistically indistinguishable between the two results. Therefore, there is no basis for advocating the use of SVD-based predictors over EOF predictors. A consequence of this statistical equivalence is that differences in coupled model results arising from the use of different predictors reflect a breakdown in the regression method. Fortunately, the coupled model results were nearly indistinguishable between the EOF and SVD regressions for modes 1 and 2. Differences were evident for higher modes. Given the uncertainty associated with the choice of flux predictors for modes higher than the second mode, the restriction of the comparisons in this study to the leading mode seems appropriate.

Seasonality of the air-sea coupling arises from different factors (Tziperman et al. 1997) and has been proposed as contributing to ENSO's irregularity (Tziperman et al. 1994; Tziperman et al. 1995) and to its tendency for warm events to reach maximum amplitude near the end of the calendar year (Tziperman et al. 1998; Galanti and Tziperman 2000). A 36-yr integration of the ECMWF hybrid model revealed that the model oscillations tend to peak between June and September. A possible source of the poor seasonal locking behavior of the model was investigated by defining the air-sea coupling on a seasonal basis. This was achieved by dividing the flux and SST time series into seasonal bins and calculating the regression based on covariance of the seasonally binned time series. During the model run, a linear interpolation between the seasonal predictor and regression patterns to the current model time was used. Warm events tend to occur somewhat earlier in the year in this case. In the context of the current model framework, the seasonality of the air-sea coupling does not favorably impact the seasonal phase-locking behavior of the model. Further sensitivity studies based on different versions of the ocean model and statistical atmospheric models are required to more fully evaluate the phase-locking behavior of the hybrid coupled model.

\section{Discussion}

The approach presented here provides a quantitative measure of air-sea flux products from AGCMs and ob- servational data by regression of surface heat and momentum flux anomalies to patterns of SST anomalies. Coupling the resulting statistical atmospheric models to an ocean GCM allows us to assess the implications of these flux products in a coupled model context. The surface flux regression is a least squares estimate of the fluxes based on predictor patterns of SST anomalies. The predictors are defined by SVD of flux-SST covariance, whereby, the SST patterns associated with the largest fraction of covariance between these fields are selected. The comparisons presented in this work are based on single predictor models defined by the leading SVD mode.

We have considered several flux products: the ECMWF and NCEP reanalyses, a satellite product (SAT) and the GFDL model. Differences in the air-sea flux anomalies between the ECMWF and NCEP reanalyses had a substantial impact on the hybrid coupled model results. The ECMWF model produced sustained oscillations while the NCEP model was oscillatory and moderately damped. The differences in the predictive skill of the models for Niño-3 SST correlation and rms error were not, however, significantly different. The GFDL hybrid model produced a strongly damped system with a significant reduction in forecast skill compared to the reanalyses. The GFDL coupled model had a strongly damped and shorter period ENSO mode at least in part due to the westward bias in the Walker circulation in the GFDL atmospheric model. The satellite product yielded an unstable (nonoscillatory) solution. This is associated with a strong evaporative feedback in the central equatorial Pacific.

A result from this work is that the hybrid coupled model is less sensitive to the magnitude of the flux anomalies than it is to their location. For instance, the NCEP flux anomalies were relatively weak compared to the GFDL anomalies; however, the NCEP hybrid model is in a less damped oscillatory regime. The flux anomalies are associated with the modulation of tropical convection, occurring mainly in the western and central Pacific. Surface latent, radiative, and momentum fluxes are linked by this mechanism. Strong winds are tied with greater evaporation and more cloudiness that tend to offset the effect of the winds, which, considered independently, would typically lead to a more unstable ENSO system.

The results presented here are dependent on the choice of ocean model and its background state, the time period of analysis, and the inclusion of modes higher than the second pattern. The results are insensitive to the choice of EOF or SVD predictor method for the leading two modes. Seasonally dependent air-sea coupling does not impact the stability of the coupled model solutions examined here, but does affect the seasonal locking behavior of the coupled model. Both the seasonally based and nonseasonal air-sea coupling models do not exhibit the observed seasonal locking behavior.

Future studies will be directed towards examining the 
use of multiple SST predictors in the coupled model and will likely incorporate filtering of the fluxes and SST prior to generating the covariances in order to minimize the impact of atmospheric noise. In addition to establishing statistical confidence, a physical understanding of additional coupled modes is important. For instance, SST-flux covariance can arise through an atmospheric response to SST anomalies or vice versa. Since statistics do not inform us about causality, a physical interpretation is necessary to provide confidence in the results. Furthermore, the sensitivity of the results will be examined in the context of higher resolution ocean models with improved physics.

Acknowledgments. Reanalysis data was provided by NOAA's Climate Diagnostic Center, and by ECMWF. The SSM/I dataset was provided by the Max Planck Meteorological Institute. The authors would like to thank Andrew Wittenberg of the Princeton Atmospheric and Ocean Sciences Program and the anonymous reviewers for their numerous comments and suggestions which contributed greatly to the quality of this manuscript.

\section{REFERENCES}

Behringer, D. W., M. Ji, and A. Leetma, 1998: An improved coupled model for ENSO prediction and implications for ocean initialization. Part I: The ocean data assimilation system. Mon. Wea. Rev., 126, 1013-1021.

Bretherton, C., C. Smith, and J. Wallace, 1992: An intercomparison of methods for finding coupled patterns in climate data. J. Climate, 5, 541-560.

Chang, P., B. Wang, T. Li, and L. Ji, 1994: Interactions between the seasonal cycle and the southern oscillation-Frequency entrainment and chaos in a coupled ocean-atmosphere model. Geophys. Res. Lett., 21, 2817-2820.

Darnell, W., W. Staylor, N. Ritchey, S. Gupta, and A. Wilber, 1996 Surface radiation budget: A long-term global dataset of shortwave and longwave fluxes. Eos, Trans. Amer. Geophys. Union, Electronic Supplement. [Available online at http://www.agu.org/ eos_elec/95206e.html].

Deser, C., and J. Wallace, 1990: Large-scale atmospheric circulation features of warm and cold episodes in the tropical Pacific. $J$. Climate, 3, 1254-1281.

Esbensen, S., and V. Kushnir, 1981: The heat budget of the global ocean. An atlas based on estimates from surface marine observations. Tech. Rep. 29, Climate Research Institute, Oregon State University, Corvallis, OR, $27 \mathrm{pp}$.

Galanti, E., and E. Tziperman, 2000: ENSO's phase locking to the seasonal cycle in the fast-SST, fast-wave, and mixed-mode regimes. J. Atmos. Sci., 57, 2936-2950.

Gibson, J., P. Kallberg, S. Uppala, A. Nomura, A. Hernandez, and E. Serrano, 1997: ERA Description. ECMWF Reanalysis Project
Report Series, No. 1, ECMWF, Reading, United Kingdom, 72 pp.

Gordon, C., and W. Stern, 1982: A description of the GFDL global spectral model. Mon. Wea. Rev., 110, 625-644.

Hellerman, S., and M. Rosenstein, 1983: Normal monthly wind stress over the world ocean with error estimates. J. Phys. Oceanogr., 13, 1093-1104.

Ji, M., D. W. Behringer, and A. Leetma, 1998: An improved coupled model for ENSO prediction and implications for ocean initialization. Part II: The coupled model. Mon. Wea. Rev., 126, 10221034.

Jin, F., J. Neelin, and M. Ghil, 1994: ENSO on the devil's staircase: Annual sub-harmonic steps to chaos. Science, 264, 70-72.

Jost, V., J. Schulz, and S. Bakan, 1999: A new satellite-derived freshwater flux climatology. Proc. Conf. on the TOGA Coupled Ocean-Atmosphere Response Experiment (COARE) Boulder, CO, World Climate Research Program, 205-207.

Kalnay, E., and Coauthors, 1996: The NCEP/NCAR 40-Year Reanalysis Project. Bull. Amer. Meteor. Soc., 77, 437-471.

Levitus, S., and T. P. Boyer, 1994: Temperature. Vol. 4, World Ocean Atlas 1994, NOAA Atlas NESDIS, 117 pp.

_, R. Burgett, and T. P. Boyer, 1994: Salinity. Vol. 3, World Ocean Atlas 1994, NOAA Atlas NESDIS, 99 pp.

Neelin, J. D., D. Battisti, A. Hirst, F. Jin, Y. Wakata, T. Yamagata, and S. Zebiak, 1998: ENSO theory. J. Geophys. Res., 103 (C7), 14 261-14 290.

Newman, M., and P. D. Sardeshmukh, 1995: A caveat concerning singular value decomposition. J. Climate, 8, 352-360.

Philander, S. G. H., and R. C. Pacanowski, 1981: Parameterization of vertical mixing in numerical models of tropical oceans. $J$. Geophys. Res., 86 (C3), 1903-1916.

Reynolds, R., and T. Smith, 1994: Improved global sea surface temperature analyses using optimum interpolation. J. Climate, 7 , 929-948.

Rosati, A., K. Miyakoda, and R. Gudgel, 1997: The impact of ocean initial conditions on ENSO forecasting with a coupled model. Mon. Wea. Rev., 125, 754-772.

Smagorinsky, J., 1963: General circulation experiments with the primitive equations. Part I: The basic experiment. Mon. Wea. Rev., 91, 99-164.

Stockdale, T. N., A. J. Busalacchi, D. Harrison, and R. Seager, 1998 Ocean modeling for ENSO. J. Geophys. Res., 103, 14325 14355 .

Stricherz, J. N., D. M. Legler, and J. J. O'Brien, 1997: TOGA Pseudostress atlas 1985-1994, Vol. II. Tech. Rep. 2, Center for OceanAtmosphere Prediction Studies, The Florida State University, $158 \mathrm{pp}$.

Syu, H., and J. Neelin, 1995: Variability in a hybrid coupled GCM. J. Climate, 8, 2121-2142.

Tziperman, E., L. Stone, M. Cane, and H. Jarosh, 1994: El Niño chaos: Overlapping of resonances between the seasonal cycle and the Pacific ocean-atmosphere oscillator. Science, 264, 72 74.

- M. Cane, and S. Zebiak, 1995: Irregularity and locking to the seasonal cycle in an ENSO prediction model as explained by the quasi-periodicity route to chaos. J. Atmos. Sci., 52, 293-306. , S. Zebiak, and M. Cane, 1997: Mechanisms of seasonal-ENSO interactions. J. Atmos. Sci., 54, 61-71.

, M. Cane, S. Zebiak, Y. Zue, and B. Blumenthal, 1998: Locking of El Niño's peak time to the end of the calendar year in the delayed oscillator picture of ENSO. J. Climate, 11, 2191-2199. 